\title{
O PAPEL DO ESTÁGIO CURRICULAR PARA A FORMAÇÃO DOCENTE: Visão dos Educandos do Curso de Licenciatura em Educação do Campo
}

\author{
Helena Maria Beling ${ }^{1}$ \\ Janete Webler Cancelier ${ }^{2}$ \\ Carmen Rejane Flores $^{3}$
}

\begin{abstract}
RESUMO
Este artigo objetiva refletir sobre a importância da realização do Estágio Curricular Supervisionado II para discentes do curso de Educação do Campo ofertado na modalidade a distância pela Universidade Federal de Santa Maria (UFSM), a partir das experiências vivenciadas pelos estagiários nas escolas. A pesquisa foi desenvolvida com alunos matriculados na disciplina de estágio da primeira oferta do curso, que abrange os polos de apoio presencial de Agudo, Cerro Largo, Itaqui, Seberi e São Sepé. A pesquisa caracteriza-se como um estudo exploratório com abordagem qualitativa. Para seu desenvolvimento utilizou-se a pesquisa bibliográfica, documental, de campo e análises. Realizamos um questionário com a ferramenta Google Formulários para descobrir o perfil dos alunos, o papel e a importância do estágio curricular para a formação docente e as dificuldades enfrentadas. As atividades do estágio possibilitam interação com diversas realidades escolares, momento no qual os estudantes são flexionados a realizar a intermediação entre os conhecimentos teóricos e práticos, buscando, a partir desta vivência, internalizar práticas que o constituem enquanto docente. Destacamos a importância dos estágios para os futuros docentes, no sentido da consolidação de práticas emancipatórias.
\end{abstract}

Palavras-chave: formação inicial; estágio; prática educativa; educação a distância.

THE FUNCTION OF THE CURRICULAR INTERNSHIP FOR TEACHING TRAINING: PERSPECTIVE OF THE STUDENTS OF THE LICENTIATE IN RURAL EDUCATION DEGREE COURSE

\begin{abstract}
This article aims to reflect about the importance of the curricular supervised internship II to the students of the Rural Education Degree Course, offered in distance modality, by the Federal University of Santa Maria (UFSM), from the experiences of the interns in the schools. The research was developed with students enrolled in the internship discipline, of the first offer that covers the support centers of Agudo, Cerro Largo, Itaqui, Seberi e São Sepé. The research is an exploratory study with a qualitative approach. To its development the bibliographic, documental and field researches and analysis were used. We conducted a Google Forms questionnaire, to discover the profile of the students, the role and importance of the curricular internship for the teaching training and the difficulties faced. The internship activities allow interaction with different school realities, moment in which the students are able to perform the intermediation between theoretical and practical knowledge, seeking from this experience to internalize practices that constitute them as teachers. We highlight the importance of the internships to the teaching future, as a way to consolidate emancipatory practices.
\end{abstract}

Keywords: initial formation; internship; educational practice; distance education.

Recebido em: $19 / 8 / 2020$

Aceito em: $15 / 11 / 2020$

\footnotetext{
1 Autora correspondente. Universidade Federal de Santa Maria - UFSM. Av. Roraima, no 1000, Cidade Universitária - Bairro Camobi. Santa Maria/RS, Brasil. CEP 97105-900. http://lattes.cnpq.br/1552124711477113. https://orcid.org/0000-0002-6356-3594. helenabeling2015@ gmail.com

2 Universidade Federal de Santa Maria - UFSM. Santa Maria/RS, Brasil. http://lattes.cnpq.br/7710315647430813. https://orcid.org/00000002-4850-5492.

3 Universidade Federal de Santa Maria - UFSM. Santa Maria/RS, Brasil. http://lattes.cnpq.br/9604409518707631. https://orcid.org/00000002-5879-2042.
} 


\section{INTRODUÇÃO}

Este artigo tem como tema apresentar a relevância da realização do segundo estágio curricular obrigatório para os educandos do curso de Licenciatura em Educação do Campo ofertado pela Universidade Federal de Santa Maria (UFSM) em parceria com a Universidade Aberta do Brasil (UAB).

A partir do Estágio Curricular Supervisionado, o discente passa a ter contato com as vivências, as experiências, as práticas pedagógicas e os momentos diversos do espaço escolar, realizando a inserção no espaço da sua profissão enquanto futuro educador bem como seu papel perante a sociedade na construção de sujeitos críticos e emancipados.

Nos cursos de Licenciatura o estágio curricular proporciona aos discentes a articulação entre teoria e prática, constituída enquanto espaço de integração entre universidade, escola e comunidade. Ao tomar como base a inter-relação teoria/prática a partir das relações citadas, os futuros docentes têm a possibilidade de consolidar sua práxis pedagógica numa perspectiva emancipatória.

Desse modo, os estagiários conseguem analisar, refletir e compreender na prática a complementaridade entre o processo de ensinar e do aprender. A convivência com distintas realidades possibilita, ao futuro professor, compreender a importância do trabalho interdisciplinar, reconhecer a pluralidade presente nos espaços escolares, conhecer a realidade dos alunos e os saberes necessários à realização da docência bem como os desafios da futura profissão. A mediação entre teoria e prática pedagógica exige domínio dos conhecimentos da área e dos saberes necessários à prática docente.

Para o estagiário, experienciar, na prática, significa aplicar de alguma forma os conhecimentos em ambientes formativos situados em distintos contextos sociais, históricos e culturais. A formação de um professor requer movimento, interação e dialogicidade. Neste contexto, a interação com o ambiente escolar é essencial para a formação profissional e para a consolidação dos saberes inerentes aos processos de ensino e aprendizagem. O estágio é “[...] o lócus onde a identidade profissional do aluno é gerada, construída e referida; volta-se para o desenvolvimento de uma ação vivenciada, reflexiva e crítica" (BURIOLLA, 1999, p. 13).

O estágio deve ser um momento de síntese dos conteúdos, das matérias de ensino, das teorias de aprendizagem e das experiências pessoais, bem como deve direcionar-se a um processo de reflexão-ação-reflexão (PIMENTA, 2006). Desta forma, o estágio oferta novas possibilidades de ensinar e aprender a profissão docente, inclusive para os professores formadores, convidando-os a rever suas concepções sobre o ensinar e o aprender (PIMENTA; LIMA, 2008).

Nesse sentido, este trabalho objetiva compreender a importância da realização do Estágio Curricular Supervisionado II para os licenciandos do curso de Educação do Campo, ofertado na modalidade a distância pela UFSM, a partir das experiências vivenciadas pelos estagiários nas escolas. 
O Estágio Curricular Supervisionado II caracteriza-se enquanto estágio de observação, sendo este o primeiro momento de inserção ativa na escola, momento no qual o estagiário acompanha as atividades desenvolvidas e a vivência em contextos educativos formais nas disciplinas de História e Geografia no Ensino Fundamental e História, Geografia, Filosofia e Sociologia no Ensino Médio. No estágio, conforme Castro (2000), os diferentes saberes aprendidos revertem-se em capacidades específicas no exercício docente ao aproximar o aluno-professor da realidade concreta do futuro campo profissional.

O fato de o curso ocorrer na modalidade a distância dificulta a presença constante do professor regente da disciplina de estágio nos espaços em que os mesmos ocorrem. Sendo assim, é essencial compreender a importância que os estagiários atribuem à prática enquanto um momento de construção da identidade docente. Os saberes vivenciados no estágio auxiliam na formação docente. O contato com a dinamicidade da escola, com distintas realidades, com suas múltiplas práticas, contribui com a formação identitária do futuro professor.

O Projeto Pedagógico do Curso (PPC) destaca que o estágio auxilia no processo de formação destes profissionais, capacitando-os para atuarem como educadores(as) em âmbito de Educação Básica, sendo Ensino Fundamental séries finais do 6으 ao 9음 ano, nas áreas de História e Geografia, e no Ensino Médio nas áreas de História, Geografia, Sociologia e Filosofia. O referido documento destaca que estes profissionais atuam, especialmente, em escolas do campo, mas não prioritariamente, não havendo, desta maneira, perante o PPC do curso, impedimentos para a realização de estágios e atuação profissional também em escolas urbanas, motivo pelo qual muitos alunos realizam seus estágios em escolas urbanas (PPC, 2017).

Desta forma, o presente trabalho justifica-se pela necessidade de evidenciar que o componente curricular do estágio não se limita apenas a ser uma prática, em que alunos de Licenciatura se dirigem às escolas para desenvolver um trabalho que faz parte da matriz curricular, sendo uma atividade de caráter burocrático, mas, sim, que este é fundamental na formação inicial de professores, tendo em vista que, no ambiente escolar, estão presentes muitas diversidades e complexidades, as quais são resultantes das inter-relações sociais, econômicas e culturais que não se manifestam de forma homogênea.

Assim, a interação, mediada pelo estágio curricular, possibilita ao estagiário a reflexão sobre o ambiente escolar e a complexidade da prática docente, bem como seu papel enquanto futuro professor na utilização de práticas de ensino pautadas para a formação de sujeitos críticos e atuantes na sociedade.

\section{LOCALIZAÇÃO DA ÁREA DE ESTUDO}

O curso de Licenciatura em Educação do Campo ocorre na modalidade a distância, e tem o intuito de formar licenciados habilitados em ciências humanas para quatro áreas do conhecimento, sendo: Filosofia, Geografia, História e Sociologia. O egresso, ao concluir o curso, estará habilitado a atuar no Ensino Fundamental nas séries finais do 60 ao 9o ano, nas disciplinas de História e Geografia, e, no ensino Médio nas disciplinas de História, Geografia, Sociologia e Filosofia (PPC, 2017). 
Atualmente, o curso é ofertado em 11 polos de apoio presencial, distribuídos entre diferentes regiões do Estado do Rio Grande do Sul (RS), que teve a oferta em dois momentos. A primeira oferta ocorreu no primeiro semestre do ano de 2017 para os polos dos municípios de Agudo, Cerro Largo, Itaqui, Seberi e São Sepé. A segunda oferta aconteceu no primeiro semestre de 2019 para os polos localizados nos municípios de Balneário Pinhal, Encantado, Novo Hamburgo, Santana do Livramento, São Lourenço do Sul e Sobradinho. A reflexão apresentada refere-se aos alunos da primeira oferta do curso, tendo em vista que estes já se encontram realizando o Estágio Curricular Supervisionado. A localização dos polos pode ser observada na Figura 1.

Os polos de apoio presencial são essenciais para a concretização do curso, uma vez que é nestes espaços que as atividades presenciais se desenvolvem. A área de abrangência do curso, contudo, vai além dos municípios-sede dos polos, havendo alunos matriculados que residem em distintos espaços e municípios dentro do Estado gaúcho. Para o polo presencial de Agudo observou-se que, além do município-sede, os alunos também residem em Cachoeira do Sul, Vera Cruz, Santa Maria, Novo Cabrais, Restinga Seca, Paraíso do Sul e Candelária. Na abrangência do polo presencial de São Sepé está o município de Caçapava do Sul. O polo presencial de Cerro Largo abarca alunos que residem nos municípios de ljuí, Três de Maio, Joia, Guarani das Missões, Santa Rosa, Catuípe, Entre-ljuís. Na abrangência do polo presencial de Seberi estão alunos dos municípios de Frederico Westphalen, Rodeio Bonito, Iraí, Tapejara e Erval Seco. Por sua vez, o polo de Itaqui, em razão da distância de demais municípios, abrange somente alunos deste município.

Figura 1 - Mapa de localização da área de estudo
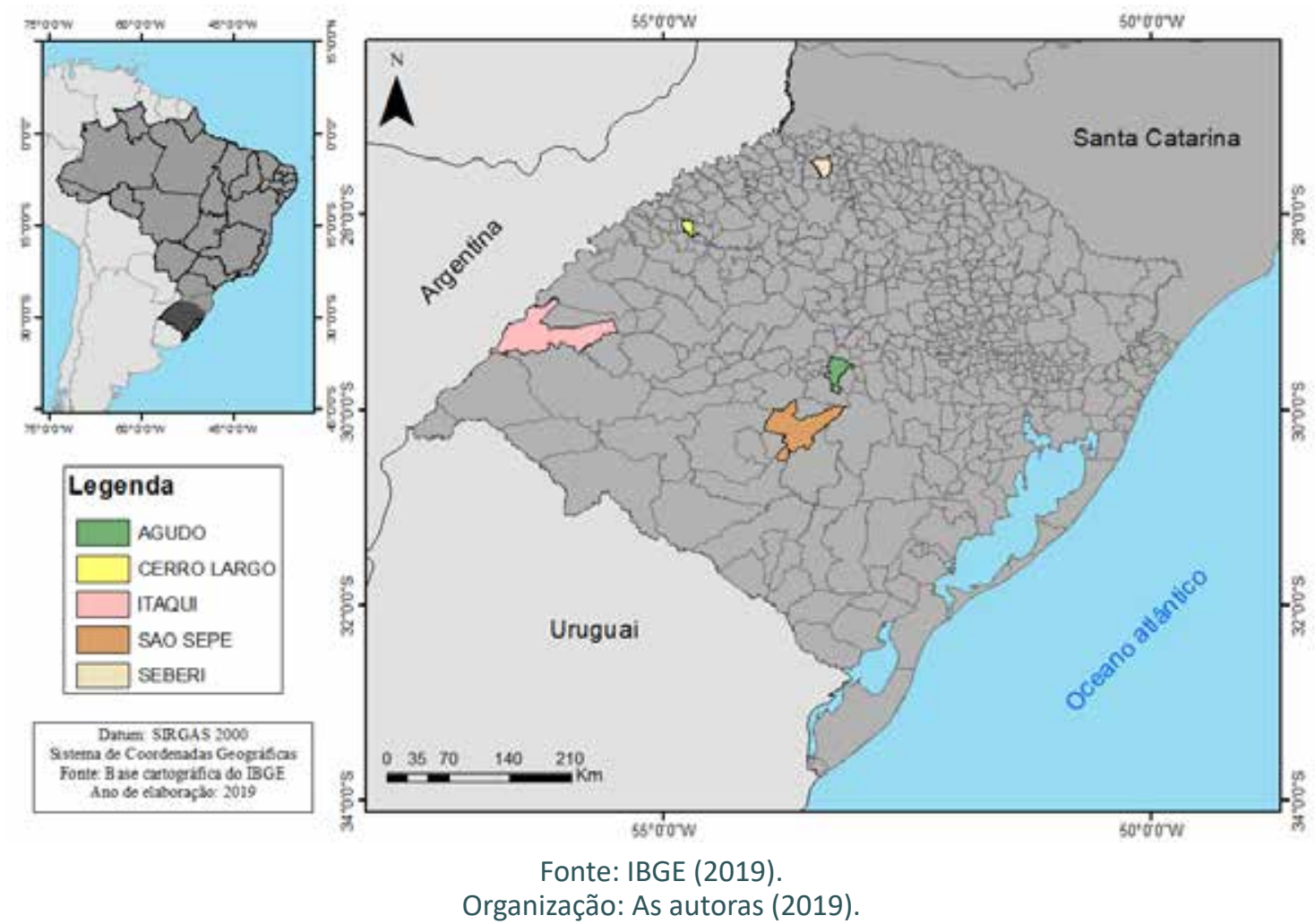


\section{PROCEDIMENTOS METODOLÓGICOS}

A pesquisa caracteriza-se como um estudo exploratório com abordagem qualitativa, e procura identificar a importância do Estágio Curricular Supervisionado para a formação inicial dos docentes, tomando como referência a visão dos discentes estagiários.

Para seu desenvolvimento utilizou-se a pesquisa bibliográfica, documental, de campo e análises. A partir do levantamento bibliográfico tornou-se possível construir o referencial teórico nas diferentes perspectivas teóricas colocadas. Os dados de fonte secundária foram obtidos na Associação Brasileira de Educação a Distância (Abed), no Instituto Brasileiro de Geografia e Estatística (IBGE) e no PPC do curso de Licenciatura em Educação do Campo da UFSM. Após a análise dos dados as informações obtidas foram representadas em gráficos, bem como a interpretação dos resultados.

Os sujeitos da pesquisa são estudantes que se encontravam no sexto semestre do curso de Licenciatura em Educação do Campo. A pesquisa empírica foi realizada no ano de 2019 com os alunos dos polos de apoio presencial dos municípios de Agudo, São Sepé, Seberi, Cerro Largo e Itaqui. Tendo em vista a distância entre os polos e a dificuldade de locomoção, optou-se por utilizar o questionário a partir da ferramenta Google Formulários, quando buscamos descobrir o perfil dos alunos, o papel e a importância atribuídos à prática do estágio curricular para a formação docente, bem como as dificuldades enfrentadas.

Para acessar os alunos em sua totalidade o formulário foi postado na plataforma utilizada pela UFSM - o Moodle -, sob o aval da professora regente na disciplina de estágio. A opção por disponibilizar o questionário na disciplina de estágio decorre do fato de os alunos, naquele momento, estarem realizando a disciplina e acessarem com maior frequência. Foi enviada uma mensagem, pelo Moodle, a todos os alunos, explicando o objetivo da pesquisa e a importância da participação, bem como todas as instruções necessárias para o acesso ao questionário.

A disciplina possui um total de 99 alunos matriculados, dos quais 54 responderam, o que representa um percentual de $54,5 \%$ do total de alunos matriculados. Os questionários foram respondidos de maneira anônima por 15 alunos do polo de Agudo, correspondendo a 27,8\% do total; por 14 alunos do polo de Seberi, ou seja, 25,9\%; 11 alunos de Itaqui, 20,4\% do total; por 7 alunos do polo de São Sepé e 7 do polo de Cerro Largo, correspondendo a $13 \%$ de cada polo. As falas dos depoentes estão nomeadas pela letra E, seguido da ordem do retorno do questionário e do ano de 2019.

\section{PERFIL DOS EDUCANDOS}

A partir da aplicação do questionário tornou-se possível descobrir o perfil dos alunos do curso de Licenciatura em Educação do Campo. Os dados, sequencialmente apresentados, são relevantes na medida em que auxiliam na compreensão de quem são estes sujeitos e a visão que possuem sobre o papel do estágio curricular.

O número de mulheres presentes no curso é significativo. No ano de 2019 estas representam $78,8 \%$ do público matriculado, enquanto os homens $22,2 \%$. Convém destacar que esses dados vão ao encontro dos dados divulgados pelo último relatório analítico da aprendizagem a distância no Brasil do Censo EAD da Abed (2019), realiza- 
do no ano de 2018 , o qual demonstra que $70 \%$ do público da educação a distância no Brasil é formado por mulheres. Entre os motivos que levam as mulheres a praticar esta modalidade de ensino está a necessidade de trabalhar o dia inteiro e a flexibilidade em organizar os horários dedicados ao trabalho, família e estudos.

Neste contexto pode-se afirmar que educação a distância, apesar das dificuldades iniciais, inerentes à utilização das tecnologias de informação e comunicação, vem se colocando como uma forma de acesso ao Ensino Superior e à democratização do conhecimento, principalmente para as mulheres, o que, inegavelmente, vem a diminuir as desigualdades sociais e de acesso em relação aos grupos historicamente excluídos, como é o caso, por exemplo, das mulheres (MARTINS, 1991).

Em relação à faixa etária, observa-se que 38,9\% dos alunos entrevistados possuem entre 31 e 40 anos, $37 \%$ entre 41 e 50 anos, 18,5\% entre 23 e 30 anos, 1,8\% entre 18 e 22 anos e $3,8 \%$ é composto por aqueles com idade de 50 ou mais, conforme apresentado na Figura 2.

Figura 2 - Idade dos entrevistados

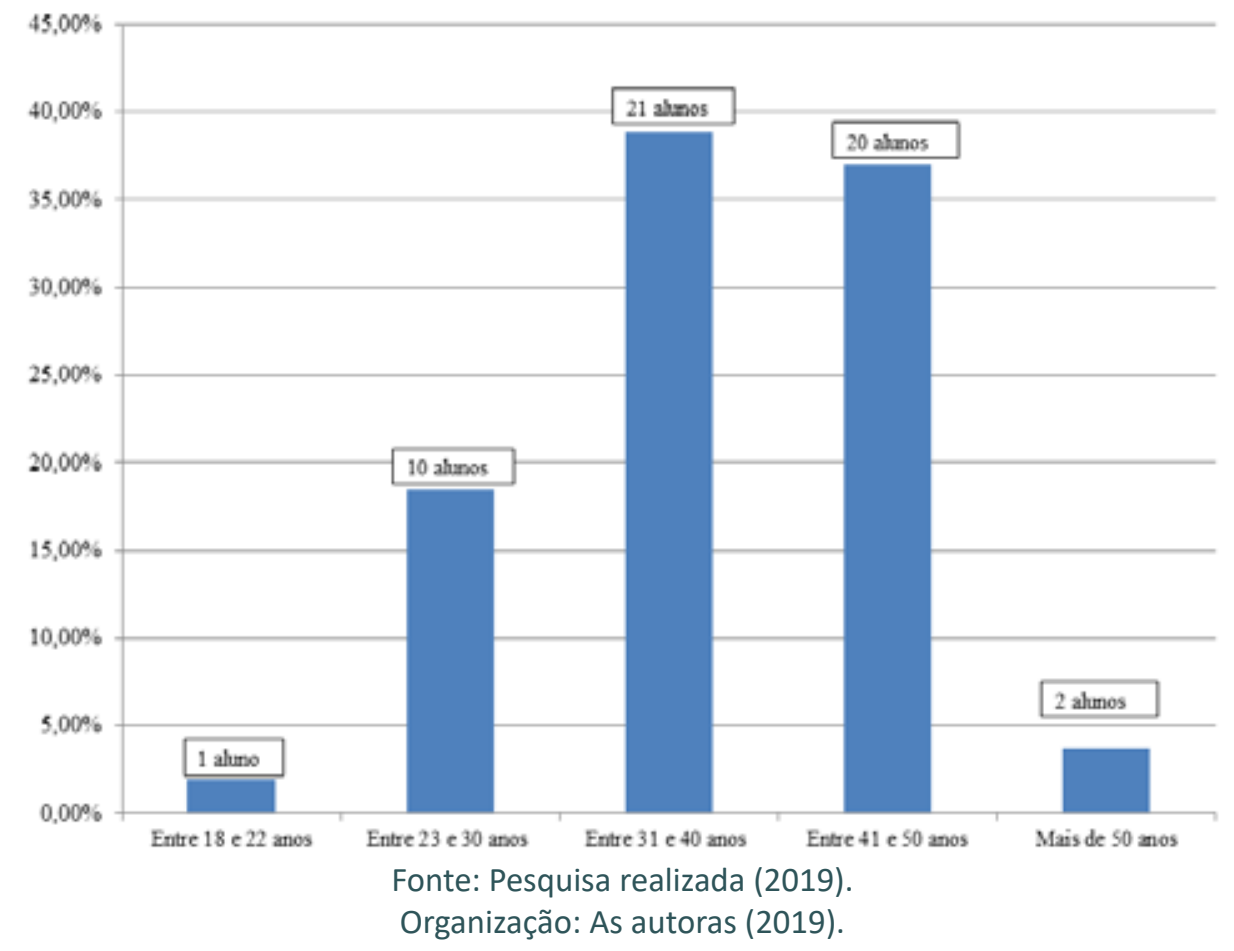

A maior incidência de alunos na idade entre 31 e 50 anos demonstra a importância da modalidade da educação a distância no acesso ao curso superior e na busca de uma formação. Esse percentual também pode ser compreendido pela inserção no mercado de trabalho, posto que há a necessidade de conciliar trabalho, família e estudo. Desta forma, a educação a distância, em decorrência da flexibilidade de horário e do acesso às plataformas de ensino, coloca-se como uma opção viável para aqueles que não conseguiram acessar a modalidade presencial. Este dado vai ao encontro do Censo da Abed do ano de 2016/2017, que destaca que mais de 75\% dos alunos de cursos regulamentados totalmente a distância estudam e trabalham. 
No que diz respeito ao grau de instrução dos discentes entrevistados, observou-se que $40,7 \%$ estão realizando a primeira Graduação e 59,3\% estão cursando a segunda Graduação. Entre as áreas iniciais de formação citadas estão: Ciências Contábeis, Engenharia Florestal, Medicina Veterinária, Gestão Ambiental, Processos Gerenciais, Pedagogia e Tecnólogo em Alimentos. Outro elemento importante verificado refere-se ao fato de que a segunda Graduação ocorre para aqueles que residem na área urbana.

Neste contexto, a opção pela Licenciatura em Educação do Campo coloca-se como possibilidade de atuar enquanto docentes ou contribuir para a qualificação profissional. Do total de alunos pesquisados, 3,8\% possuem Pós-Graduação em grau de Doutorado, aqueles que já possuem Especialização representam 29,6\%, e os que estão realizando a segunda graduação $25,9 \%$ do total, conforme apresentado na Figura 3.

Figura 3 - Escolaridade dos entrevistados

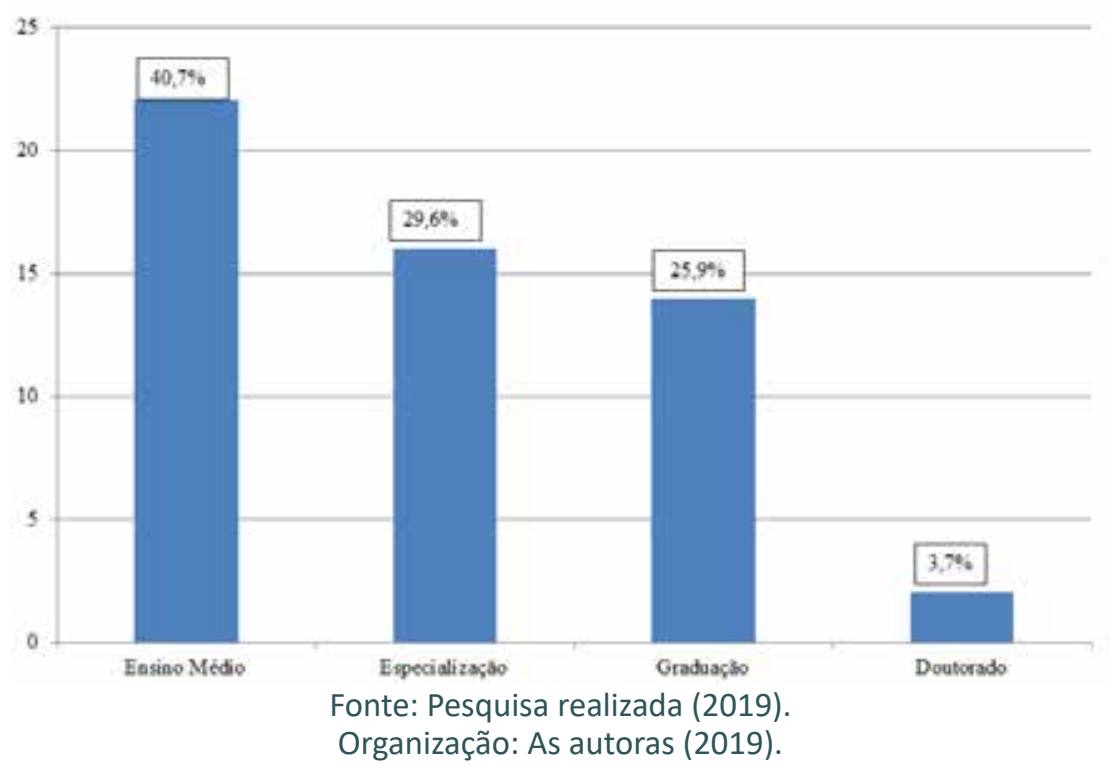

Entre os motivos citados que levaram a optar pelo curso de Licenciatura em Educação do Campo estão: a especificidade da oferta na modalidade a distância, a gratuidade do curso como uma oportunidade única, melhores possibilidades de acesso ao mercado de trabalho, nome da instituição que oferta o curso, comodidade e flexibilidade na organização de seus horários.

Quanto às atividades profissionais exercidas, verificou-se que $83,3 \%$ possuem trabalho fixo, atuando no comércio e serviços, como funcionalismo público geral e em áreas da educação pública nas esferas municipal, estadual e federal, destacando-se o cargo de docente, merendeiras, serviços gerais e monitores.

No que se refere ao espaço de moradia dos depoentes, quanto ser em área urbana ou rural, percebe-se que é representativo o número de alunos residentes na área urbana. Os mesmos compõem $74,1 \%$ do grupo, enquanto os residentes no espaço rural somam $25,9 \%$ do grupo, representando, respectivamente, 40 e 14 alunos. A oferta da internet no espaço rural tem possibilitado o acesso às plataformas de ensino sem necessitar de deslocamento até a sede do polo de apoio presencial, o que tem ampliado a participação dos alunos residentes no meio rural. 
De acordo com o Censo EAD.BR (ABED, 2019), em 2018, no Brasil, o acesso à internet nas áreas rurais ampliou-se em $44 \%$. Esta realidade tem possibilitado novas oportunidades, como o acesso à educação superior. O IBGE (2019), em sua publicação que versa sobre o Censo Agropecuário, contudo, salienta que $71,8 \%$ das propriedades rurais no Brasil ainda estão sem acesso à internet. Desta forma, apesar do avanço na disponibilidade da internet, as dificuldades para estudar ainda são maiores para aqueles que residem no espaço rural, uma vez que estes estão à mercê de problemas estruturais que, muitas vezes, impossibilitam, inclusive, o acesso à educação básica.

\section{O ESTÁGIO CURRICULAR SUPERVISIONADO}

No período de realização do estágio os discentes têm a oportunidade de vivenciar, na prática, a futura profissão. Essa etapa caracteriza-se também enquanto um período de aprendizado, pois o estagiário ainda pode retornar à universidade para esclarecer dúvidas, dialogar e debater sobre o observado. Esse movimento de ir e vir entre escola e universidade, ao longo da realização do curso, possibilita o desenvolvimento de saberes, habilidades e competências necessárias à prática docente, fortalecendo a construção da identidade do futuro docente. Seguindo esta linha de pensamento, Almeida e Pimenta (2014, p. 73) salientam que:

Durante o curso de graduação começam a ser construídos os saberes, as habilidades, posturas e atitudes que formam o profissional. Em períodos de estágio, esses conhecimentos são ressignificados pelo aluno estagiário a partir de suas experiências pessoais em contato direto com o campo de trabalho que, ao longo da vida profissional, vão sendo reconstruídos no exercício da profissão.

As atividades desenvolvidas durante a realização do estágio, quando bem planejadas e sistematizadas, de acordo com Lugle e Magalhães (2013), permitem, aos professores em formação, reflexão e construção crítica de suas metodologias de trabalho, especialmente compreendendo a importância do seu papel de educador na formação humana. O estágio é uma etapa para questionar, problematizar e compreender a dinâmica vivenciada no dia a dia no ambiente escolar. "A profissão de professor é prática e, o modo de aprender a profissão, [...] será a partir da observação, imitação, reprodução e, às vezes, da reelaboração dos modelos existentes na prática, consagrados como bons" (PIMENTA; LIMA, 2008, p. 7).

Desta forma, considera-se essencial que o estágio se consolide enquanto momento e espaço de reflexão, mediado pelo confronto entre teorias e práticas. O estagiário precisa ter condições de apreender a(s) teoria(s) que a sustenta(m) e poder realizar uma leitura pedagógica para além do senso comum (GOMES, 2009). Esse enfrentamento permite ampliar as concepções sobre o que é ensinar e aprender a partir de subsídios teóricos e práticos.

Esse conhecimento envolve o estudo, a análise, a problematização, a reflexão e a proposição de soluções às situações de ensinar e aprender. Envolve experimentar situações de ensinar, aprender a elaborar, executar e avaliar projetos de ensino não apenas nas salas de aula, mas também nos diferentes espaços da escola (PIMENTA; LIMA, 2012, p. 55). 
Inserido neste contexto está o Estágio Curricular Supervisionado II, realizado pelos alunos do 60 semestre do curso de Licenciatura em Educação do Campo da UFSM, o qual oportuniza condições aos alunos para conhecer, por meio da observação, a estrutura e o funcionamento do ambiente escolar. Neste momento ainda sistematizam o ambiente escolar a partir das práticas didáticas e pedagógicas nas disciplinas de História, Geografia, no Ensino Fundamental e História, Geografia, Filosofia e Sociologia no Ensino Médio. Este período caracteriza-se como o primeiro contato com a realidade do espaço escolar.

A disciplina Estágio Curricular Supervisionado II possui uma carga horária total de 75 horas, das quais 25 horas foram trabalhadas sob orientação do professor e tutor com discussões acerca da importância do estágio, dos documentos, das etapas a serem contempladas e da elaboração e escrita do relatório final de estágio. As demais 50 horas foram realizadas em escolas e divididas em duas fases. Na primeira os estagiários realizaram um diagnóstico da escola, caracterizando sua estrutura, público, turmas, turnos, o espaço em que está inserida (urbano ou rural) e práticas desenvolvidas que possuem relação com a educação do campo (hortas, trabalhos de recuperação de áreas degradadas com o reflorestamento, trabalhos com relação à identidade cultural).

Sequencialmente analisaram o Projeto Político Pedagógico (PPP) da escola no sentido de averiguar quais apontamentos estavam presentes em relação ao contexto do espaço em que a escola está inserida, a Concepção Filosófica-Pedagógica que a escola adota e a relação com a educação do campo. Na segunda etapa ocorreu a observação em sala de aula das práticas pedagógicas nas disciplinas de Geografia e História do Ensino Fundamental e das disciplinas de Geografia, História, Filosofia e Sociologia do Ensino Médio.

A partir das etapas realizadas, os futuros professores passam a ter contato com distintas realidades, o que lhes permite compreender que as escolas se organizam de distintas formas, com públicos diferenciados, que é necessário desenvolver diversificadas estratégias didáticas e pedagógicas, bem como adotar uma postura investigativa no processo de ensino e aprendizagem, buscando viabilizar a aprendizagem dos alunos. Esse processo de formação, segundo Rosa (2006), cumpre um importante papel social para a inserção dos futuros professores na lógica da ordem social e contribui na análise crítica da realidade com o objetivo de torná-lo melhor.

Nessa perspectiva, torna-se necessário reconhecer a importância que a universidade possui na consolidação das bases que sustentam a formação inicial do professor. Da mesma maneira, verificar a constituição de um sujeito crítico, reflexivo, capaz de interpretar a realidade e realizar articulações entre os conhecimentos da universidade e da escola a partir de suas referências técnico-científicas internalizadas no período em que se encontra na Graduação.

A esse respeito, Santos (2006) destaca que a integração entre pesquisa e ensino na formação de professores possibilita o desenvolvimento de atitudes investigativas, levando-os a detectar os problemas do cotidiano escolar e a buscar as soluções na literatura, na utilização de diferentes recursos e na troca de experiências com os colegas. 
O estágio, em sua essência, possibilita que o futuro professor vivencie uma relação horizontalizada entre os conhecimentos da universidade e da escola. Busca, a partir de suas práticas, consolidar um professor que pensa, interpreta, media e associa a dimensão técnica científica ao contexto de atuação docente e aos diferentes saberes e conhecimentos presentes no espaço escolar. Desta forma, o estágio é essencial para a formação inicial e a constituição do professor, afirmação que é corroborada por 98,1\% dos entrevistados, e apenas um depoente relatou que o estágio não auxiliou na sua formação.

Ainda que o Estágio Curricular Supervisionado II se caracterize pela observação das metodologias e práticas didáticas e pedagógicas adotadas pelos professores regentes das turmas, os entrevistados destacaram a importância pelo contato que permitiu convívio com a realidade do espaço escolar e na confrontação inicial dos fundamentos teóricos com a prática. Este fato que é corroborado pelo entrevistado E-48 (2019), ao relatar que:

Eu não tinha dimensão de como é estar em uma escola na posição de educadora, me abriu horizontes, me deu muito medo, do tamanho da responsabilidade que é ter o futuro de dezenas de crianças e jovens nas mãos... E me deu muita esperança, por que sei que a educação transforma! E minha admiração por estas professoras só cresceu.

Para o depoente E-16 (2019) foi uma nova experiência, haja vista que sua vivência em sala era somente na condição de aluno. A condição de estagiário o colocou em outra perspectiva, quando passou a ser visualizado pelos alunos como professor, o que foi desafiador e motivador. E-16 (2019) relata, ainda: “[...] a partir desta experiência me sinto mais seguro para realizar o estágio seguinte, onde atuarei na condição de estagiário docente nas disciplinas de história e geografia do Ensino Fundamental".

A inter-relação entre teoria e prática, alinhada ao contato escolar, é destacada pelos entrevistados como elementos positivos do estágio que contribuem na constituição docente. A esse respeito, E-41 (2019) salienta: “[...] diante das observações percebi que uma aprendizagem significativa depende muito da prática e do comprometimento do docente com os alunos".

As concepções pedagógicas que constituem os futuros docentes são construídas em diferentes tempos e espaços, e, neste processo de formação, de acordo com os entrevistados, o estágio contribui significativamente, o que pode ser observado nas seguintes falas:

O estágio foi um momento muito importante na minha caminhada como estudante do curso de Licenciatura em Educação do Campo. Através do estágio tive a oportunidade de conhecer melhor a realidade da modalidade EJA, como os professores se organizam, como essa modalidade funciona, como são as aulas e através disso fiquei encantada e apaixonada pelas aulas e isso, com certeza mostra o quanto este estágio contribuiu na minha formação (E-4, 2019).

O estágio trouxe vários conhecimentos para minha futura profissão. Observar o espaço escolar e assistir as aulas possibilitou uma visão ampla de como está sendo aplicado o ensino das disciplinas de história, geografia, filosofia e sociologia nas escolas. Notei as mudanças que já aconteceram desde a minha formação tanto no 
ensino fundamental quanto no médio, o quanto a educação evoluiu e ainda o que precisa ser melhorado. Ir de encontro a realidade desses jovens, acompanhar as aulas, os principais questionamentos, as dificuldades de alunos e professores que atuam nessas áreas, foi muito gratificante. Perceber o olhar de confiança e ao mesmo tempo cheio de dúvidas desses alunos, experiência vivenciada no período do estágio, me fez ainda ter mais vontade de prosseguir no caminho da docência e na busca por educação de qualidade (E-10, 2019).

Os relatos apresentados evidenciam a visão dos entrevistados em relação ao estágio, sendo possível perceber já estar presente a percepção de seu papel de futuros professores como agentes de transformação social, no sentido de buscar ofertar uma educação de qualidade sem perder de vista a dimensão técnico-científica. A esse respeito, Libâneo (2004, p. 137) ressalta que

[...] existe a necessidade de reflexão sobre a prática a partir da apropriação de teorias como marco para as melhorias das práticas de ensino, o professor é ajudado a compreender o seu próprio pensamento, a refletir de modo crítico sobre sua prática e, também, a aprimorar seu modo de agir, seu saber-fazer, à medida que internaliza novos instrumentos de ação.

Quando questionados se encontraram dificuldades para a realização do Estágio, $64,8 \%$ dos entrevistados relataram que não tiveram. Estes salientaram que tiveram ótima recepção e atenção da equipe escolar e dos alunos, além das orientações para a realização do estágio. A esse respeito E-8 (2019), relata: “[...] a realização do estágio foi bem tranquila, a relação estabelecida com professores e alunos foi proveitosa e me proporcionou momentos de muito aprendizado".

Os que tiveram dificuldades representam $35,2 \%$ do grupo. Para estes, as maiores adversidades estão relacionadas aos deslocamentos diários e à necessidade de conciliar horários entre os períodos que estão em seus trabalhos e os que devem estar nas escolas, tendo em vista que, para estes, é frequente o trabalho ocorrer em um município e o estágio em outro. Este grupo, em sua maioria, está composto por alunos com idade acima dos 31 anos. Também foi citada a situação precária em que se encontram as escolas mantidas pelo Estado. Apesar das dificuldades relatadas, todos os entrevistados concluíram as atividades práticas do estágio.

O estágio é uma etapa muito importante possibilitando experiências próprias da atividade na qual estamos nos preparando. Foi possível perceber que nas aulas planejadas por mais simples que sejam, o professor conseguiu desenvolver um bom trabalho. A convivência com os alunos, o contato com direção, supervisão e professores possibilitou uma interação mais próxima ao cotidiano e as aprendizagens em sala de aula $(E-23,2019)$.

Ao serem questionados sobre as disciplinas que mais chamaram atenção, tendo em vista que o estágio foi realizado na observação de História e Geografia no Ensino Fundamental e História, Geografia, Filosofia e Sociologia no Ensino Médio, 96,3\% dos entrevistados citaram História e Geografia nos dois níveis. De acordo com os mesmos, estas disciplinas ocorreram de forma mais dinâmica e interativa em relação às disciplinas de Sociologia e Filosofia. Os professores de História e Geografia apresentavam 
atividades diversificadas, objetivando ampliar o processo de ensino e aprendizagem, articulando o conhecimento teórico à prática vivenciada pelos alunos, como pode ser observado a partir da fala do entrevistado E-8 (2019) a seguir:

As disciplinas que mais me chamaram a atenção foram geografia e história, pois o professor pode explorar uma infinidade de temas relacionados ao passado, possibilitando conhecer e ler o mundo, aumentando o poder de reflexão dos alunos, possibilitando a formação de indivíduos mais críticos, entendendo de que forma ele atua na sociedade e de que forma pode atuar. Conhecendo e questionando como pode se projetar o futuro com uma sociedade mais justa. As aulas destas disciplinas eram práticas com métodos que utilizavam mapas, globo, vídeos e documentários que permitiam voltar ao passado e também conhecer diversos lugares sem sair da sala de aula.

Referente às disciplinas de Filosofia e Sociologia, foi enfatizada a importância das mesmas, sobretudo, nas conversas sobre temas atuais e, assim, despertando o interesse e participação dos alunos, auxiliando no desenvolvimento do espírito reflexivo e crítico destes.

Pensando na possibilidade da futura inserção nos espaços escolares enquanto docentes, os entrevistados foram incitados a refletir, tomando como referência sua vivência no estágio como formas de potencializar o processo de ensino aprendizagem. As respostas mostraram-se similares no sentido de que $96,3 \%$ dos entrevistados compreendem ser necessário diversificar as atividades e os métodos de ensino, propiciando momentos de debates e troca de conhecimentos e saberes. Esse resultado demonstra que o estágio estimula uma postura investigativa e reflexiva dos futuros professores em relação às práticas docentes a serem adotadas.

Tomando como referência sua área de formação, foi perguntado aos entrevistados se nas escolas em que estagiaram observaram alguma temática ou prática vinculada aos conhecimentos da educação do campo, lembrando que os estágios ocorreram em escolas localizadas nas zonas urbanas e rurais. Do total dos entrevistados, 35 responderam que não e 19 que sim, o que representa, respectivamente, 64,8\% e 35,2\% dos entrevistados.

De acordo com os entrevistados, as escolas que trabalham temas voltados ao campo são aquelas localizadas no espaço rural, ainda que nem todas sejam realmente escolas do campo e sim escolas localizadas no campo. As práticas materializam-se pela presença das hortas escolares com produção de alimentos que são utilizados para complementar a merenda escolar ofertada aos alunos.

Também observaram que na disciplina de Geografia são realizadas aulas práticas e teóricas vinculadas ao conhecimento e cuidados com jardim, pomar da escola, à sustentabilidade com a inserção da Agroecologia e a distribuição de plantas nativas à comunidade escolar, buscando preservar as nascentes e matas. Outro exemplo citado refere-se à disciplina de Sociologia, onde o professor realiza inserções acerca da importância do homem do campo e as dificuldades na relação homem $x$ sociedade na sociedade contemporânea (E-9, 2019).

Ainda que as ações desenvolvidas estejam vinculadas à realidade local, faz-se necessário um maior envolvimento da esfera pública no debate e na consolidação da escola do campo, no atendimento das necessidades educacionais e na qualificação dos professores, no sentido de que suas práticas sejam contextualizadas com a realidade local. 
Por sua vez, os entrevistados que realizaram o estágio em escolas urbanas foram questionados sobre quais práticas e/ou temáticas voltadas ao campo poderiam ser introduzidas nestes espaços. Os destaques foram para a construção da horta escolar, haja vista que existe disponibilidade de espaço; abordar temas de sustentabilidade e de educação ambiental com a valorização dos saberes do campo; o desenvolvimento de práticas agrícolas embasadas na agroecologia e os benefícios destes alimentos para a saúde; trabalhar com os alunos a origem dos alimentos servidos na merenda escolar.

É nesse contexto que o entrevistado E-38 (2019) enfatiza que

[...] o campo é de suma importância para todos nós, é de onde vem nosso alimento, precisamos realizar atividades que promovam essa valorização, inclusive na escola que realizei o estágio a merenda escolar é oriunda da agricultura familiar, porém os alunos não têm esse entendimento, falta uma reflexão.

Para Freire (2011, p. 40), não há docência comprometida com a formação do humano sem reflexão sobre a ação; "[...] é pensando criticamente a prática de hoje ou de ontem que se pode melhorar a próxima prática".

No que se refere à sua futura inserção profissional no mercado de trabalho, enquanto docentes, 90,7\% dos entrevistados mostram-se preocupados, tendo em vista que ainda são poucos os editais que ofertam vagas com a possibilidade de inserção para os licenciados em Educação do Campo, principalmente nas redes municipais de educação. Na rede estadual de educação do Estado do Rio Grande do Sul já são disponibilizadas vagas nos editais.

Os entrevistados destacaram que ocorre uma falta de valorização dos sujeitos do campo e esse processo reflete-se pela ineficiência das ações das políticas públicas, principalmente as educacionais, no fortalecimento das escolas do campo. Ainda que as Diretrizes Operacionais para a Educação Básica do Campo tenham sido aprovadas no ano de 2002, a lentidão em seu estabelecimento dificultou seu alcance e efetivação. Desta forma, a escola nas comunidades rurais não sofreu transformações significativas, estando no campo sem pertencer a ele (WIZNIEWSKY, 2010). A esse respeito, o depoente E-31 (2019) destaca que "a falta de políticas públicas educacionais com viés a este público e o fechamento das escolas localizadas na zona rural, somadas à carência de professores com formação acadêmica compatível, são as maiores dificuldades enfrentadas".

Nesse contexto, destaca-se a necessidade da instituição de uma educação voltada para os sujeitos e a vida no campo que atenda suas reais necessidades. Construir uma escola do campo significa estudar para viver no campo, ou seja, inverter a lógica que se estuda para sair do campo. A escola do campo deve ser um lugar onde crianças e jovens possam sentir orgulho de sua origem a partir da compreensão dos problemas que existem no campo (CALDART, 2008).

Assim, colocamos a importância da formação inicial dos educadores e o papel dos estágios curriculares nesta formação. As atividades propostas oportunizam aos educandos(as) situações de ensino na Educação Básica que possibilitem a aplicação de conhecimentos, a formação de atitudes, o desenvolvimento e o aperfeiçoamento de habilidades necessárias à prática educativa, promovendo novas formas de pensar e agir comprometidas com a consolidação e uma educação emancipatória. 


\section{CONSIDERAÇÕES FINAIS}

O estágio de observação, realizado pelos educandos do 60 semestre do curso de Licenciatura em Educação do Campo, possibilitou uma maior aproximação com a realidade de atuação dos estudantes em formação. Esses momentos são imprescindíveis na formação inicial dos professores. A vivência experienciada permite aos futuros professores desenvolver habilidades necessárias à prática docente.

Assim, o estágio é um campo de conhecimento dos futuros docentes, e, por sua vez, cria aberturas e possibilidades para os futuros professores se confrontarem às diversas, próximas e reais realidades do exercício da docência. Desse modo, o estágio possibilita edificar as percepções que, no futuro, proporcione aos licenciados o desenvolvimento de uma prática docente que seja de qualidade, humana e justa.

No processo de formação docente e aprimoramento das práticas pedagógicas, a relação estabelecida entre teoria e prática oportuniza subsídios para as futuras práticas didático-pedagógicas no sentido de qualificar a práxis educativa e consolidar uma educação libertadora como bem estabelece Paulo Freire.

Nos cursos de Licenciatura, realizados na modalidade EaD, como é o caso do curso de Licenciatura em Educação do Campo, o estágio, enquanto prática curricular que ocorre presencialmente nos espaços escolares, oportuniza, além do contato com o contexto escolar, o processo de reflexão das práticas didático-pedagógicas dos professores em formação.

A formação docente no ensino a distância merece atenção, pois encontra-se em ampla expansão e precisa ser garantido com qualidade. Nesse sentido, faz-se necessário capacitar o licenciando em formação na relação entre a teoria e a prática. Quando o docente compreende essa correlação e faz uso, em sua prática docente, oportuniza uma aprendizagem significativa e auxilia na formação de sujeitos críticos e emancipados.

É preciso investir na formação do professor; não apenas na formação acadêmica inicial, mas também na formação continuada. Com um professor bem preparado em sua formação inicial e com formação continuada, é possível atender às necessidades e especificidades que surgem ao longo do tempo e nas distintas realidades. Assim, os alunos, educação e toda a sociedade são beneficiados.

Com base na pesquisa podemos concluir que os saberes docentes são construídos e constituídos ao longo da trajetória formativa e profissional do docente. Neste processo, a formação inicial é importante na medida em que é o primeiro contato do futuro professor com conhecimentos específicos da docência. É no estágio que o educador em formação constrói e solidifica a base para a sua formação e, posteriormente, sua atuação profissional.

Na contemporaneidade, período caracterizado por significativas mudanças, principalmente em termos educacionais, com constantes ataques às instituições de Ensino, reflexões sobre a formação dos professores são essenciais na medida em que as instituições de Ensino Superior possuem papel central na formação de docentes e nas mudanças que podem se manifestar na sociedade a partir das ações destes docentes. Desta 
forma, oportunizar tais discussões permite visualizar como as práticas pedagógicas são consolidadas nos cursos de Licenciatura. Sem essas reflexões as salas de aula podem se constituir como espaço de reprodução do tradicionalismo didático e pedagógico.

Ademais, para ter educação de qualidade é preciso investimentos e políticas sólidas, contínuas e efetivas que abarquem a formação inicial e continuada dos professores, constituindo-se, assim, em uma formação que não seja restrita ao aprender para ensinar, mas que possibilite a construção do conhecimento e a formação de sujeitos críticos que embasem suas práticas a partir da ação-reflexão.

\section{AGRADECIMENTOS}

Agradecemos aos alunos da disciplina de Estágio Curricular Supervisionado II do curso de Licenciatura em Educação do Campo UAB/UFSM que participaram da pesquisa respondendo o questionário.

\section{REFERÊNCIAS}

ALMEIDA, Maria Isabel; PIMENTA, Selma Garrido. Estágios supervisionados na formação docente. São Paulo: Cortez, 2014.

ABED. Associação Brasileira de Educação a Distância. Censo EaD 2016. Disponível em: http://www.abed. org.br/site/pt/midiateca/censo_ead/. Acesso em: 10 jun. 2019.

ABED. Associação Brasileira de Educação a Distância. Censo EAD.BR. Relatório analítico da aprendizagem a distância no Brasil 2018. Livro eletrônico. Organização ABED. Tradução Camila Rosa. Curitiba: InterSaberes, 2019. Disponível em: http://abed.org.br/arquivos/CENSO_DIGITAL_EAD_2018_PORTUGUES.pdf. Acesso em: 23 jul. 2020.

BURIOLLA, Marta A. Feiten. O estágio supervisionado. 2. ed. São Paulo: Cortez, 1999.

CALDART, Roseli Salete. Sobre educação do campo. In: SANTOS, C. A. (org.). Campo - políticas públicas educação. Brasília: Incra; MDA, 2008. (Por uma Educação do Campo, no 7).

CASTRO, Maria Aparecida Campos Diniz de. Abrindo espaço no cotidiano para o estágio supervisionado: uma questão do olhar e da relação na formação inicial e em serviço. 2000. 230 p. Tese (Doutorado) - Pontifícia Universidade Católica de São Paulo, PUC-SP, 2000.

FREIRE, Paulo. Pedagogia da autonomia: saberes necessários à prática educativa. São Paulo: Paz e Terra, 2011.

GOMES, Marineide de Oliveira. Formação de professores na educação infantil. São Paulo: Cortez, 2009. (Coleção docência em formação. Série educação infantil).

IBGE. Instituto Brasileiro de Geografia e Estatística. Censo Agropecuário 2017. Rio de Janeiro, v. 8, 2019. Disponível em: https://biblioteca.ibge.gov.br/visualizacao/periodicos/3096/agro_2017_resultados_definitivos.pdf. Acesso em: 15 jul. 2020.

LIBÂNEO, José Carlos A aprendizagem escolar e a formação de professores na perspectiva da psicologia histórico-cultural e da teoria da atividade. Educar, Curitiba, n. 24, 2004.

LUGLE, Andreia Maria Cavaminamo; MAGALHÃES, Cassiana. O papel do estágio na formação do professor dos anos iniciais do Ensino Fundamental. Revista Eletrônica Pro-Docência/UEL, n. 4, v. 1, p. 119-128, jul./dez. 2013. Disponível em: http://www.uel.br/revistas/prodocenciafope/pages/arquivos/Volume4/ TEXTO\%2012\%20-\%20p.\%20119\%20a\%20128.pdf. Acesso em: 20 jun. 2020.

MARTINS, Onilza Borges. A educação superior à distância e a democratização do saber. Petrópolis, RJ: Vozes, 1991.

PIMENTA, Selma Garrido; LIMA, Maria Socorro Lucena. Estágio e docência: diferentes concepções. 3. ed. São Paulo: Cortez, 2008.

PIMENTA, Selma Garrido; LIMA, Maria Socorro Lucena. Estágio e docência. São Paulo: Cortez, 2012.

PIMENTA, Selma Garrido. O estágio na formação de professores: unidade teoria e prática? 7. ed. São Paulo: Cortez, 2006.

PPC. Projeto Pedagógico de Curso. Licenciatura em educação do campo. Santa Maria, RS: Universidade Federal de Santa Maria, 2017. 
ROSA, Dalva E. Gonçalvez. Formação de professores: concepções e práticas. In: CAVALCANTI, L. de S. (org.). Formação de professores: concepções e práticas em geografia. Goiânia: Vieira, 2006.

SANTOS, Lucíola L. C. P. Dilemas e perspectivas na relação entre ensino e pesquisa. In: ANDRÉ. M (org.). O papel da pesquisa na formação e prática dos professores. 5. ed. Campinas. SP: Papirus, 2006. p. 11-26. WIZNIEWSKY, Carmen Rejane Flores. A contribuição da geografia na construção da educação do campo. In: MATOS, K. S. A. L. de; WIZNIEWSKY, C. R. F.; DE DAVID, C. de (org.). Experiências e diálogos em educação do campo. Fortaleza: Edições UFC, 2010. 